\title{
Kalçanın cerrahi dislokasyonu (güvenli kalça çıkığı)
}

\author{
Surgical dislocation of the hip joint (SHD)
}

\author{
ilker Abdullah Sarıkaya', Gürkan Çalışkan² \\ ${ }^{1}$ Çocuk Ortopedi Kliniği, Şişli İstanbul \\ ${ }^{2}$ Kanuni Sultan Süleyman Eğitim Araştırma Hastanesi, İstanbul
}

\begin{abstract}
Kalçanın cerrahi dislokasyonu, temel olarak, kalça eklemine posterolateral girişim ile ulaşılmasını ve kalçanın anteriora dislokasyonunu içerir. Bu yöntem, başta femoroasetabular sıkışma olmak üzere, kalça ekleminin intraartiküler ve ekstraartiküler birçok patolojisinin tedavisinde ön plana çıkan cerrahi yöntem olarak görülmektedir. Kalçanın cerrahi dislokasyonu ile, kalça ekleminin asetabular ve femoral kısımlarına ait anatomik yapılara tam olarak ulaşılabilmesi mümkün olur. Ayrıca, bu yöntemle mediyal femoral sirkumfleks arterin korunması sağlanarak, femur başının beslenmesinin zarar görmesi önlenir.
\end{abstract}

Anahtar sözcükler: mediyal femoral sirkumfleks arter; femoroasetabular sıkışma; avasküler nekroz; kalça cerrahisi
Surgical dislocation of the hip joint (SHD) basically includes posterolateral exposure and anterior dislocation of the hip. SHD is accepted as an important surgical treatment method for the intraarticular and extraarticular hip pathologies, especially for the femoroacetabular impingement. SHD provides access to all anatomical structures of the acetabular and femoral portion of the hip joint. Besides, medial femoral circumflex artery is protected with this technic and consequently, damage of the femoral head blood supply is avoided.

Key words: medial femoral circumflex artery; femoroacetabular impingement; avascular necrosis; hip surgery

olarak görüntülenememesi sayılabilir. ${ }^{[20-23]}$ Kalça cerrahisine özgü bu teknik zorlukları ve olası komplikasyonları göz önüne alarak, Ganz, kalça eklem patolojilerini daha iyi görüntülemeyi hedefleyen ve bunu yaparken de femur başının arteriyel dolaşımına hasar vermeyeceğini ön gördüğü, kalçanın cerrahi dislokasyonu (güvenli kalça çıkığı) yöntemini geliştirmiş̧tir. ${ }^{[6,24]}$

Labrumun, femur başı ve asetabular kıkırdağın görüntülenmesi ve ilgili patolojilere tanı konulabilmesi, günümüzde mevcut görüntüleme yöntemleri ile her zaman mümkün olamamaktadır. ${ }^{[25]}$ Ayrıca, kalçanın anterior girişimi (Smith-Peterson) ile femur başı tam olarak görünür hale gelebilse de, gluteus medius ve tensör fasya lata geniş bir biçimde sıyrılmadıkça, asetabular patolojilere tanı konabilmesi olanaksızdır. Aynı şekilde, kalça eklemine anterolateral ve lateral girişim yollarıyla ulaşılırken de asetabulum tam olarak muayene edilememektedir. ${ }^{[26,27]}$ Kalça eklem patolojilerine yönelik tedavi alternatiflerinden olan artroskopinin de kendine özgü zorlukları ve olası komplikasyonları

- İletişim adresi: Dr. İlker Abdullah Sarıkaya, Çocuk Ortopedi Kliniği. Hakkı Yeten Caddesi, Unimed Centre Kat: 9 Fulya Şişli İstanbul Tel: 0532 - 7329740 e-posta: drsarikayailker@gmail.com

- Geliș tarihi: 23 Ocak 2015 Kabul tarihi: 23 Ocak 2015 
vardır. ${ }^{[21,28,29]}$ Uzamış eklem distraksiyonu, iyatrojenik eklem hasarı, ekstravaze olan sıvının yol açtığı patolojiler, özellikle posterior asetabular eklem yüzüne tam olarak ulaşılamaması, teknik özelliklere ve ekipmana dayanan güçlükler, bunlar arasında sayılabilir. Sonuç olarak Ganz, artroskopinin güçlüklerini ve trokanter majörün salim bırakıldığı tüm açık yöntemlerde ekleme ulaşmanın zorluğunu göz önüne alarak, kalçanın cerrahi dislokasyonu yöntemini uygulamaya başlamıştır. ${ }^{[30-33]}$ Böylelikle, hem asetabular hem de femoral eklem yüzeyleri $360^{\circ}$ 'lik bir açıyla gözlenebilmekte, başta FAS'a neden olan patolojiler olmak üzere, intraartiküler ve ekstraartiküler kalça patolojileri tam olarak ortaya konabilmektedir.

Femur başı arteriyel dolaşımının temel kaynağı, mediyal femoral sirkumfleks arterdir (MFSA). ${ }^{[24,34,35]}$ MFSA a.femoralisten ya da a.profunda femoristen köken alır ve posteriora doğru yönelerek beş dala ayrılır: Bunlar, yüzeyel, derin, asetabular, inen, çıkan ve derin dallardır. Femur başının beslenmesinde önemli bir rol üstlenen derin dal, obturator eksternus kasının alt sınırını takiben intertrokanterik kristaya doğru ilerler ve kalça eksternal rotator kasları arasından yukarı yönlenir. MFSA'nın derin dalı kalça eklem kapsülünü superior gemellus ve priformis tendonlarının arasından geçerek deler ve bu noktada dallara ayrılır; bu dallar, femur başını kemik-kıkırdak sınııının yaklaşık $4 \mathrm{~mm}$ kadar aşağısından deler. Kalça eklemine posterior girişimde, kalça eksternal rotator kasları ile beraber femur başının dolaşımının da hasar göreceği bilinir. Kalçanın cerrahi dislokasyonu ile amaçlanan, başta MFSA'nın yakın iştirakli olduğu obturator eksternus kası olmak üzere, kalça ekleminin posteriorunda konuşlanan yumuşak dokuları korunmak ve femur başının ana beslenme kaynağına zarar vermemektir (Şekil 1). ${ }^{[36-38]}$

\section{ENDIKASYONLAR}

Kalçanın cerrahi dislokasyonu, labruma, asetabular ve femoral eklem yüzeylerine ulaşmayı sağlayan, başta FAS'ın intraartiküler ve ekstraartiküler nedenleri olmak üzere, birçok patolojinin tedavisinde yol gösterici olan bir cerrahi yöntemdir. ${ }^{[31,38-46]}$ Bu yöntem, Legg-Calvé-Perthes gibi FAS'a ve osteoartrite neden olan hastalıklarda, labrum onarımında, sıkışmaya neden olan asetabular kemik patolojilerinin ortadan kaldırılmasında, femur baş-boyun osteokondroplastilerinde kullanılır. Ayrıca, yüzey artroplastisinde, trokanterik kaydırma osteotomisinde, femur başı ve asetabulum kırıklarının repozisyonunda, femur başı epifiz kayması redüksiyonunda, tümör rezeksiyonunda, osteokondritis dissekansın cerrahi tedavisinde ve sinoviyal kondromatozis gibi yaygın eklem

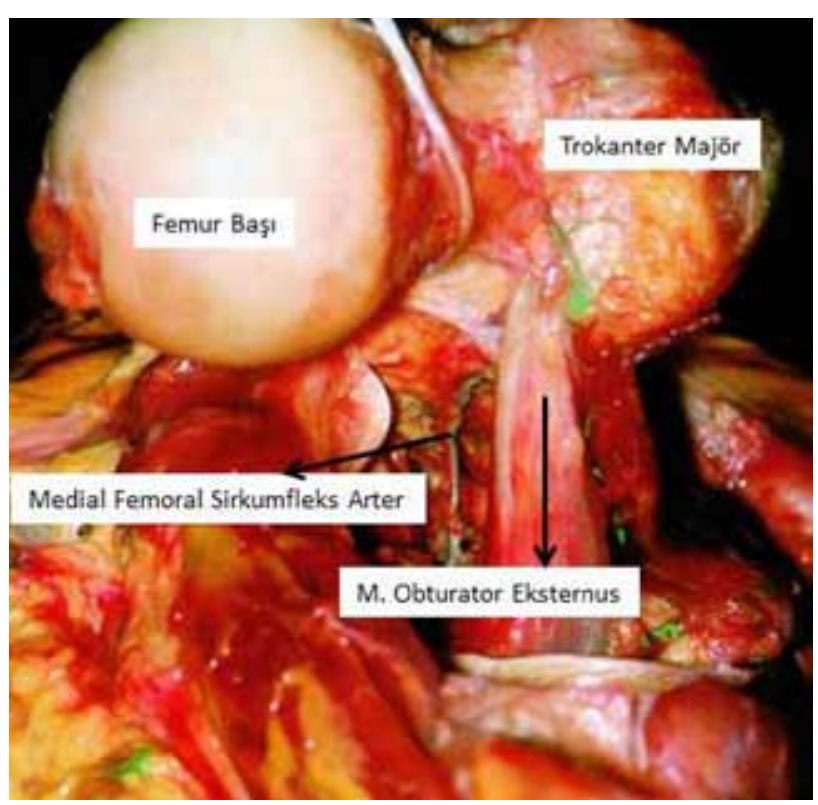

Şekil 1. Kalçanın cerrahi dislokasyonunu takiben MFSA femur ilişkisi.[24]

debridmanının gerekli olduğu olgularda, uygun yaş aralığı ve patolojiye özgü diğer özellikler de göz önüne alınarak uygulanır.

Literatürde, FAS tedavisinde kalçanın cerrahi dislokasyonu ile \%65-96'ya varan başarılı sonuçlar bildirilmektedir. ${ }^{[4,10,47-51]}$ Bu noktada en önemli hususun, uygun hasta seçimi olduğu ileri sürülmektedir. Kondral hasarın sınırlı olması, genç yaş, labral hasarın onarılabilir düzeyde olması ve hafif-orta seviyede artrit, olumlu prognostik etmenler olarak saptanmıştır. Ileri yaş, cerrahi öncesi şiddetli ağrı, ileri derece artrit, kondral hasarın geniş olması ise olumsuz prognostik etmenler olarak kabul edilir.

\section{AMELIYAT TEKNIĞi}

Cerrahi teknik, temel olarak, kalça eklemine posterolateral girişim ile ulaşılmasını ve kalçanın anteriora dislokasyonunu içerir. MFSA kalça eksternal kas grubu salim bırakılarak korunurken, eklem kapsülüne trokanterik osteotomi vasıtasıyla anteriordan ulaşılır. ${ }^{[24]}$

\section{Ameliyat öncesi planlama}

Ameliyat öncesi radyolojik muayene eksiksiz bir şekilde gerçekleştirilmeli, patoloji ve tedavi biçimi tespit edilmelidir. Standart pelvis AP ve kalça lateral grafileri çekilmeli; labral kemikleşme, osteofit oluşumları, koksa vara, valga, anterior ofset yetmezliği değerlendirilmelidir. MR artrografi ile, labral hasarın lokasyonu ve kıkırdak yüzey hakkında bilgi edinilmelidir. 


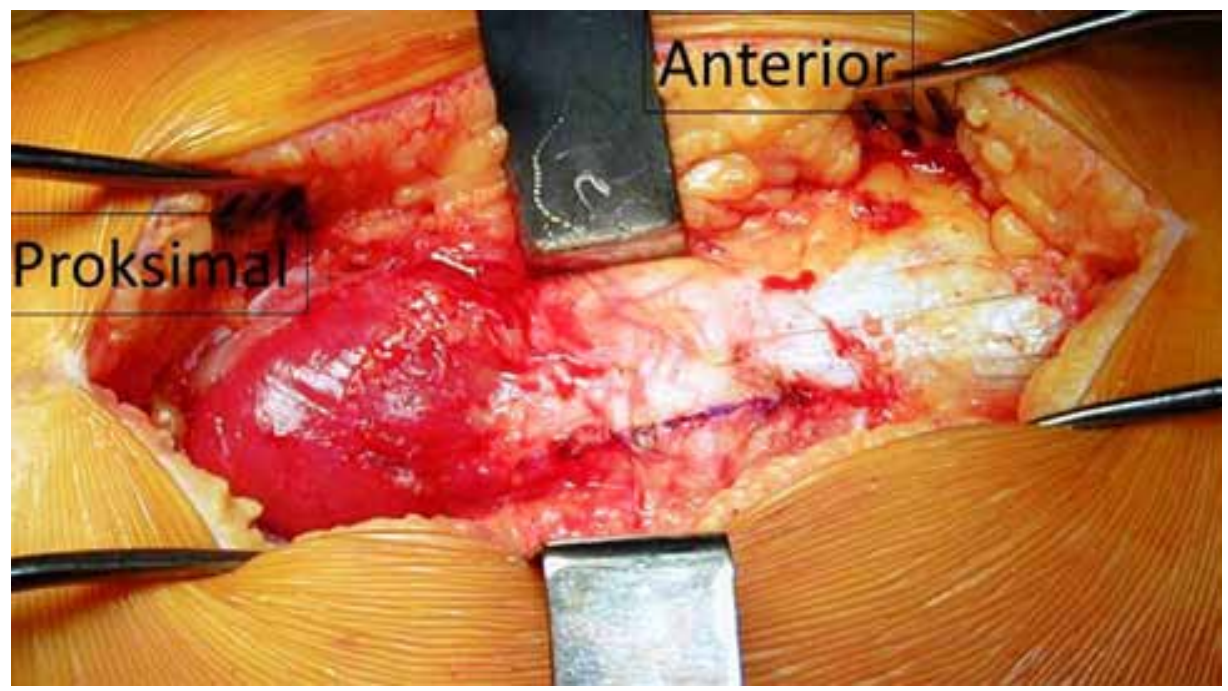

Şekil 2. Cilt insizyonunu takiben m.gluteus mediusun görünümü.

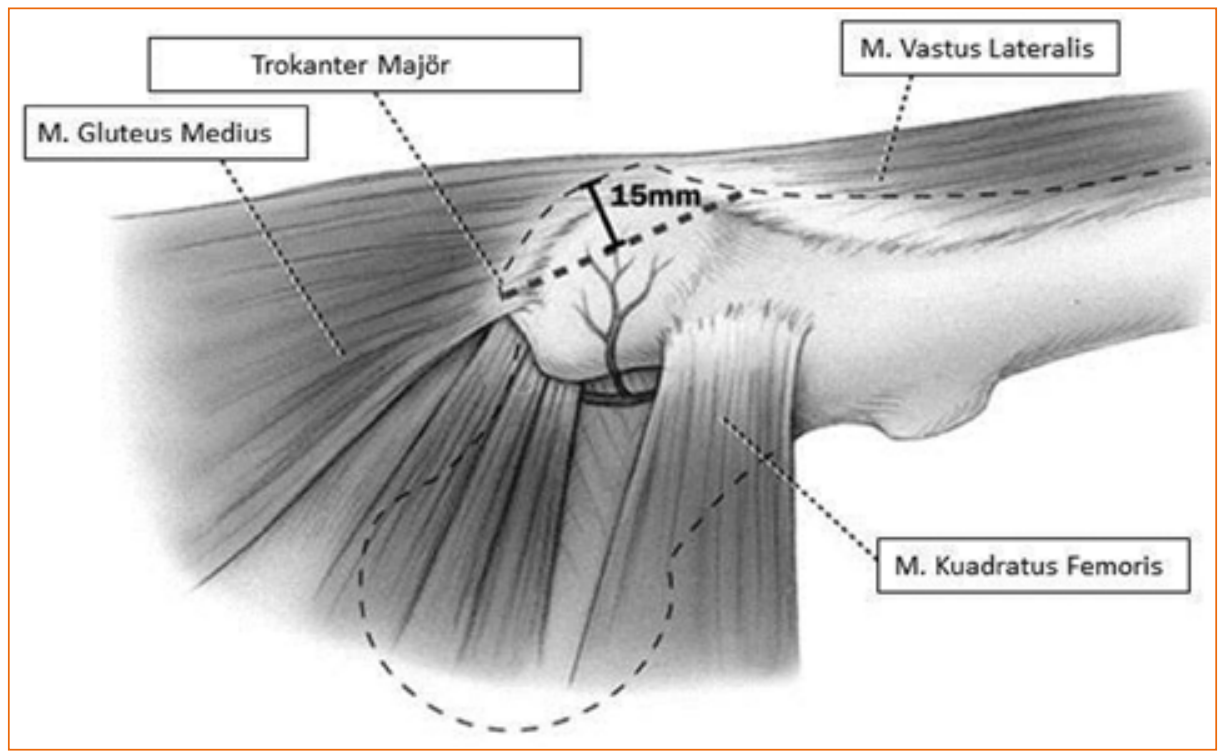

Şekil 3. Trokanterik osteotomi hattı, MFSA ve kalça eksternal rotator kaslarının ilişkisi. ${ }^{[36]}$

\section{Ameliyat tekniği}

\section{Hasta pozisyonu}

Hasta, lateral dekübit pozisyonda, kalça hareketleri kısıtlanmayacak, spina iliaka anterior superior ve inferior palpe edilebilecek şekilde konumlandırılmalıdır. Cerrahi işlem esnasında osteotominin fiksasyonu ve femur başı kanlanması hakkında bilgi verebilecekleri için, floroskop ve Doppler ultrasonografi (US) kullanılabileceği akılda tutulmalıdır. ${ }^{[35]}$

\section{Cilt insizyonu ve yumuşak doku disseksiyonu}

Trokanter majörün anterior kenarı boyunca uzanan yaklaşık 20-25 cm'lik lateral cilt insizyonu gerçekleştirilir. Bunu takiben fasya lata, keskin disseksiyonla uzunlamasına, cilt insizyonu boyunca fakat gluteus maksimus liflerine zarar vermeyecek şekilde disseke edilir. Trokanterik bursa ve eşlik eden yumuşak dokular temizlenir. Kalça internal rotasyona zorlanarak m.gluteus medius görünür hale gelir (Şekil 2).

\section{Trokanterik osteotomi}

Trokanter majörün posterosuperior köşesinden vastus lateralisin posterioruna uzanan bir disseksiyon yapılarak, trokanter majör ortaya çıkarılır ve bu disseksiyon hattını takiben, $15 \mathrm{~mm}$ kalınlığında kemik fleb oluşturacak şekilde, trokanter majör osteotomisi yapılır (Şekil 3). Osteotomi hattı trokanter majörün posterosuperior sınırından başlar, femur cismi uzun 


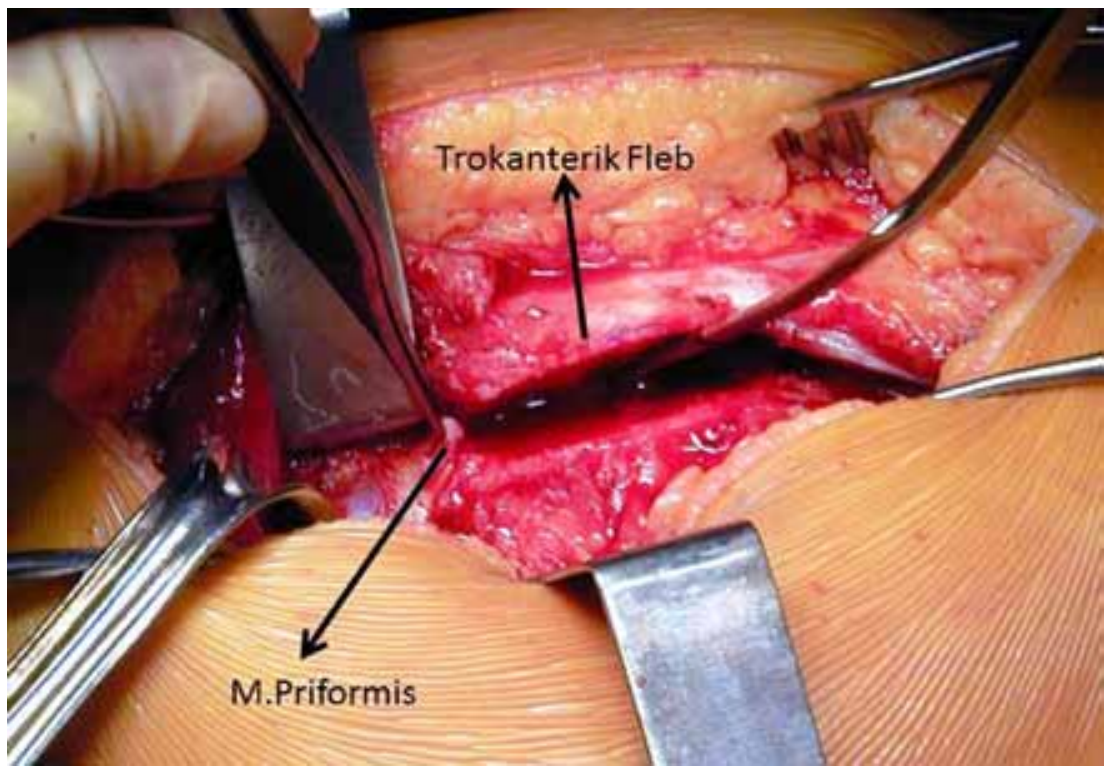

Şekil 4. Trokanterik osteotomi sonrası kemik fleb.

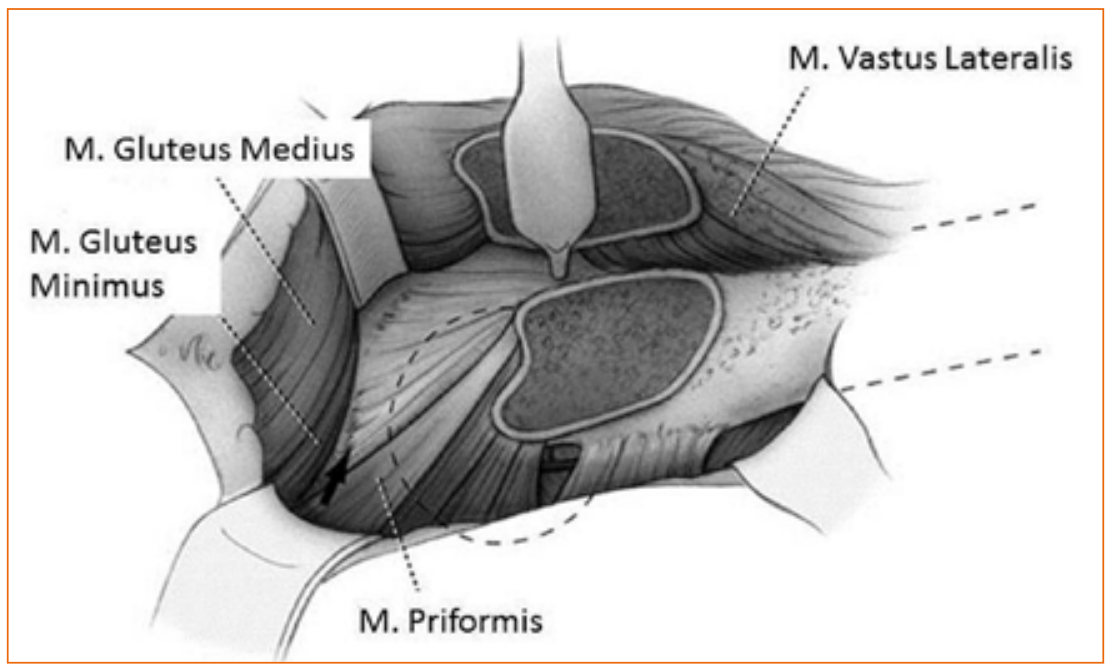

Şekil 5. Trokanterik osteotomi sonrası kalça eklem kapsülü..[36]

aksına paralel olarak vastus lateralisin posterior sınırına değin uzatılır. Kemik fleb, proksimalde m.gluteus medius ve minimus ile ve distalde vastus lateralis ile devamlılık gösterirken, kalça eksternal rotatorları osteotomize edilmemiş femur üzerinde kalmalıdır (Şekil 4). Osteotomi, proksimalde m.gluteus mediusun posterior sınırının anterioruna değin uzanır.

Osteotomize edilen kemik fleb, kendisine yapışmış olan vastus lateralis ile birlikte anteriora ilerletilir. M.gluteus mediusun posterior lifleri ve eğer mevcutsa m.priformisin lifleri kemik fleb üzerinden sıyrılır. Kalça fleksiyona ve eksternal rotasyona zorlanır, vastus lateralis ve $\mathrm{m}$. gluteus intermedius ekarte edilir. Böylelikle $\mathrm{m}$. priformis görünür hale gelirve sonrasında m.gluteus minimus, m.priformisten ve eklem kapsülünden sıyrılır. Bu aşamada, inferior gluteal arter ile MFSA arasındaki anastomoz ve m.priformisin hemen arkasında seyreden siyatik sinir korunmalıdır. ${ }^{[52]}$ Daha sonra, kemik fleb anteriora ve superiora ilerletilir ve eklem kapsülünün anterior, superior ve posterosuperior kısımları görünür hale gelir (Şekil 5).

\section{Kalça eklemine giriş}

Eklem kapsülü " $Z$ " şeklinde insizyon ile disseke edilir. ilk olarak, femur boynundan trokanter majörün üst sınırına uzanan doğrusal kapsül kesisi yapılır. Daha sonra, insizyon posterosuperiora yönelerek asetabulumun üst kenarına doğru uzatılır. Son 


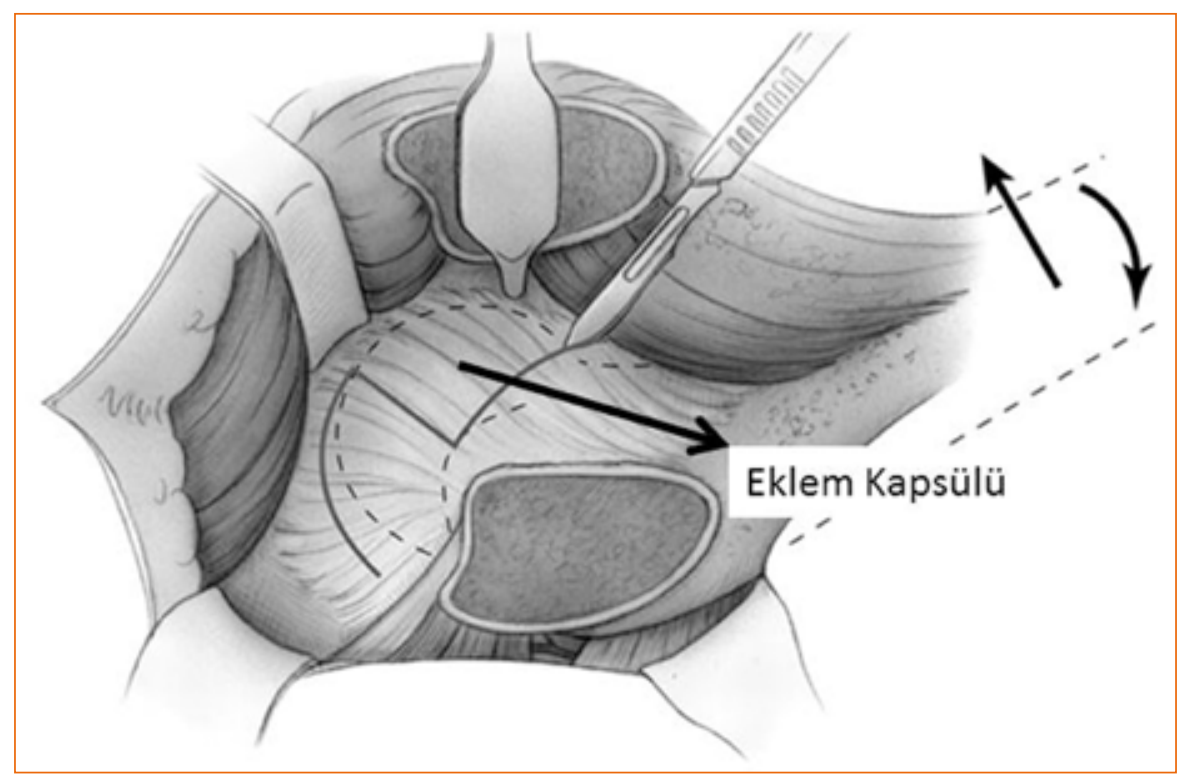

Şekil 6. Kapsülotomi. ${ }^{[36]}$

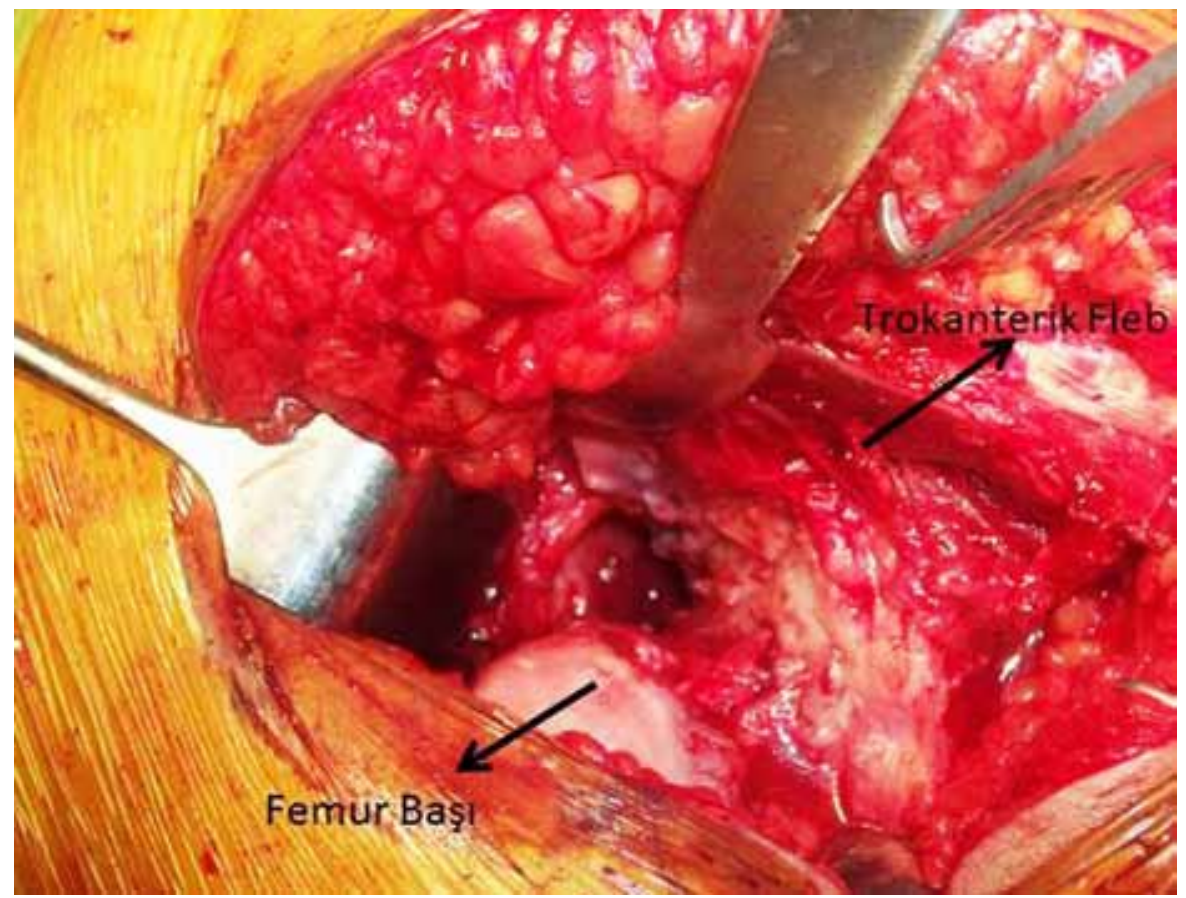

Şekil 7. Kalçanın anteriora dislokasyonu.

olarak, kapsül kesisi inferomediyal yönde trokanter minörün anterioruna doğru uzatılır (Şekil 6). Kapsül kesisi esnasında, labrum, kıkırdak yapılar ve MFSA korunmalıdır.

\section{Kalça ekleminin dislokasyonu}

Kalça, traksiyon fleksiyon ve eksternal rotasyon manevrası ile ve gerekli olunan hallerde bir çengel vasıtasıyla disloke edilir (Şekil 7). Ligamentum teres, dislokasyonun tamamlanmasına engel olacağından, eklemin tam disloke edilmesinin gerekli olduğu olgularda disseke edilmelidir.

Eklem muayenesine, sinoviyal effüzyon varlığının sorgulanmasıyla başlanır. Daha sonra, asetabular kıkırdak ve labrum muayene edilir. Asetabular kemik yapı, pincer tipi FAS açısından değerlendirilir. Asetabulumun değerlendirilmesinin ardından, femoral kısmın muayenesine geçilir. 


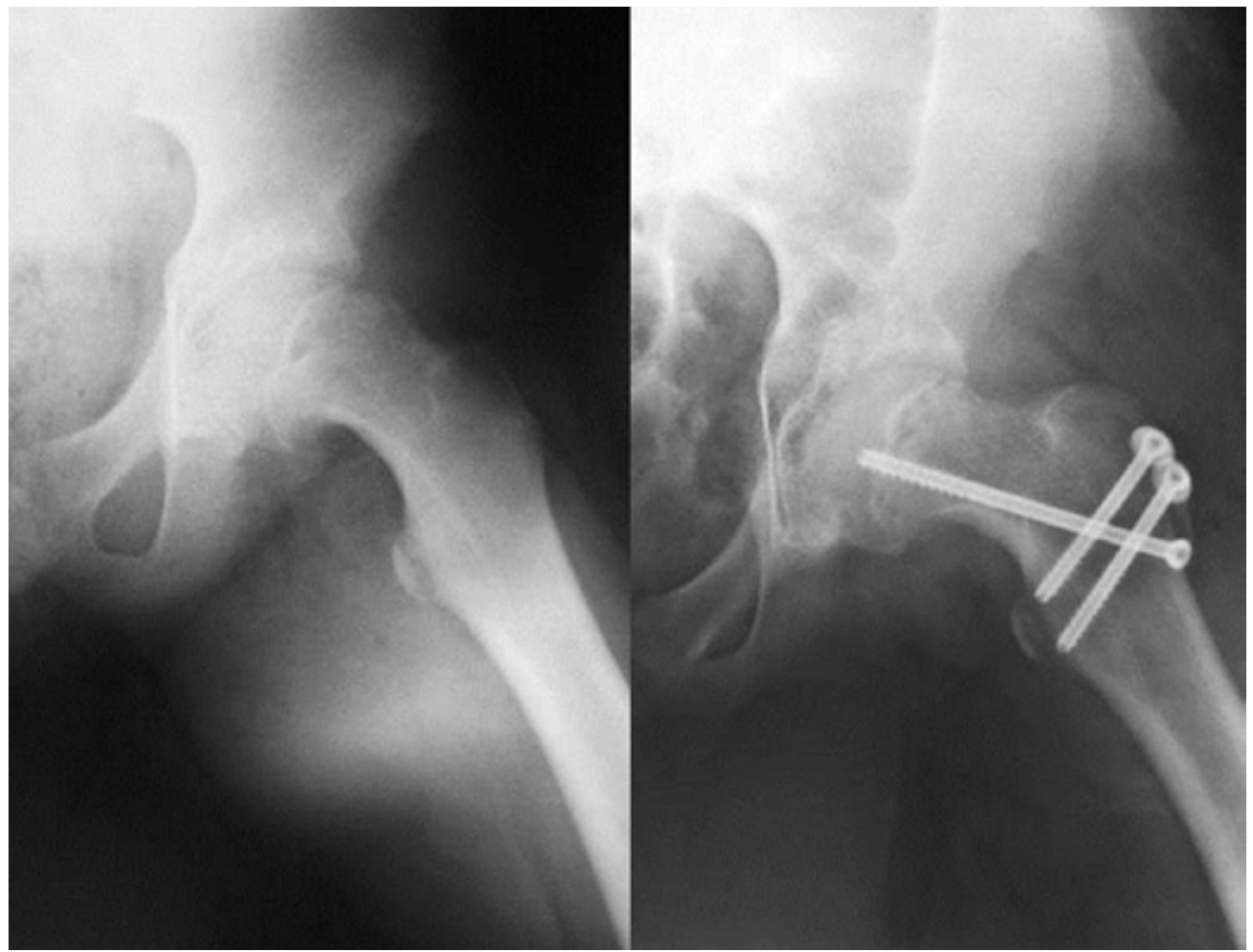

Şekil 8. Kalça cerrahi dislokasyon olgusu. Femur başı epifiz kayması redüksiyon ve femur boynu osteoplastisi ameliyat öncesi ve ameliyat sonrası kalça direkt grafileri.

\section{Asetabular tarafin tedavisi}

Asetabular labrum künt bir probe vasitasıly muayene edilir; Labrum hasarı saptanması durumunda bu hasarın onarılabilir olup olmadığı değerlendirilmelidir. Labrumun onarılamaz olarak kabul edildiği olgularda labrum debridmanı ya da greft ile rekonstrüksiyonu yöntemlerine başvurulmalıdır. Asetabular kıkırdak hasarına yönelik onarıcı tüm yöntemler kalçanın cerrahi dislokasyonu kapsamında uygulanabilmektedir. Pincer tipi FAS'a sebebiyet veren asetabulumun üst duvarına ait kemik kısım osteotomize edilebilir. Asetabular patolojilerin tedavisini takiben femoral kısma geçilir.

\section{Femoral tarafin tedavisi}

Femur başının sferikliği kontrol edilir. Sferik olmayan femur başı genelde baş-boyun bileşkesinin anterolateralinde kıkırdak ve kemik oluşumu ile kendini gösterir. Eğri osteotomlar vasıtası ile femur başının sferik olmayan bölümü şekillendirilir. Femur baş-boyun bileşkesinin anterolateral bölümü, posterolateral bölümle kıyaslandığında, MFSA yerleşimine göre daha güvenlidir. Posterolaterale uzanan sferiklik kusurunda, osteotominin ana damarlara hasar verme riski arttığı için, daha dikkatli olunmalıdır.
Kalça ekleminin redükte edilmesi ve trokanterin onarılması

Tanı koyucu ve tedavi edici işlemleri takiben, kalça eklemi hafif traksiyon uygulanarak ve internal rotasyona zorlanarak redükte edilir. Redüksiyon işlemi esnasında, başta asetabular labrum olmak üzere, kıkırdak yüzeylere zarar verilmemesi büyük önem taşımaktadır. Kalça eklem kapsülü, retinaküler arterlere zarar vermeyecek sıkılıkta onarılır. Osteotomize edilmiş olan trokanterik fleb, repoze edilmeli ve $3,5 \mathrm{~mm}$ ya da $4,5 \mathrm{~mm}$ kanüllü vidalar vasıtasıyla tespit edilmelidir (Şekil 8).

\section{Ameliyat sonrası bakım}

Hastaya, altı hafta süre ile tam yük vermemelidir. Bu süre boyunca, düşük molekül ağırlıklı heparin kullanmalıdır. Kalçaya $90^{\circ}$ üzerinde fleksiyon ve aktif abduksiyon yaptırılmamalıdır. Ameliyat sonrası ilk günde, $90^{\circ}$ 'ye kadar pasif fleksiyona başlanabilir.

\section{KOMPLIKASYONLAR}

Kalçanın cerrahi dislokasyonunu takiben, aşııı kanama, tromboemboli ve yüzeyel cilt enfeksiyonu gibi minör komplikasyonlar nadir görülür. İyatrojenik femur başı avasküler nekrozu, trokanterik kaynamama, implant ilişkili trokanter majör ağrısı, labral tespit kaybı, 
iyatrojenik femur kırığı, derin enfeksiyon, semptomatik heterotopik ossifikasyon, yetersiz osteokondroplasti, siyatik sinir arazı gibi majör komplikasyonlar \%0-6 oranında görülür. ${ }^{[18]}$

MFSA'nın anatomisinin tam olarak anlaşılması ve cerrahi esnasında vasküler yapılara gerekli özenin gösterilmesi, görülme olasılığı oldukça nadir olan iyatrojenik avasküler nekrozunun önüne geçilmesini sağlayacak etmenler arasında ilk sırayı alır. Trokanterik kaynamama, genellikle yetersiz tespit veya immobilizasyon ile ilintili olmakla beraber, literatürde \%1,9-20 gibi bir sıklıkla bildirilmektedir. ${ }^{[51-53]}$ Trokanterik kaynamama olgularında, ikinci bir cerrahi girişimle yeterli tespitin sağlanması ve immobilizasyon gerekliliği ortaya çıkar. İyatrojenik femur boynu kırığının önüne geçmek için, ameliyat öncesi radyolojik incelemenin eksiksiz bir şekilde yapılmış olması ve femur boynunun aşırı bir biçimde tıraşlanmasının önüne geçilmiş olması gerekir.

\section{KAYNAKLAR}

1. Ito K, Minka MA 2nd, Leunig M, Werlen S, Ganz R. Femoroacetabular impingement and the cam-effect. A MRIbased quantitative anatomical study of the femoral headneck offset. J Bone Joint Surg Br 2001;83(2):171-6.

2. Ganz R, Parvizi J, Beck M, Leunig M, Nötzli H, Siebenrock KA. Femoroacetabular impingement: a cause for osteoarthritis of the hip. Clin Orthop Relat Res 2003;(417):112-20.

3. Nötzli HP, Wyss TF, Stoecklin $\mathrm{CH}$, Schmid MR, Treiber K, Hodler J. The contour of the femoral head-neck junction as a predictor for the risk of anterior impingement. J Bone Joint Surg Br 2002;84(4):556-60.

4. Beck M, Kalhor M, Leunig M, Ganz R. Hip morphology influences the pattern of damage to the acetabular cartilage: femoroacetabular impingement as a cause of early osteoarthritis of the hip. J Bone Joint Surg $\mathrm{Br}$ 2005;87(7):1012-8.

5. Ganz R, Leunig M, Leunig-Ganz K, Harris WH. The etiology of osteoarthritis of the hip: an integrated mechanical concept. Clin Orthop Relat Res 2008;466(2):264-72. CrossRef

6. Ganz R, Gill TJ, Gautier E, Ganz K, Krügel N, Berlemann $U$. Surgical dislocation of the adult hip a technique with full access to the femoral head and acetabulum without the risk of avascular necrosis. J Bone Joint Surg $\mathrm{Br}$ 2001;83(8):1119-24.

7. Beck M, Leunig M, Parvizi J, Boutier V, Wyss D, Ganz R. Anterior femoroacetabular impingement: part II. Midterm results of surgical treatment. Clin Orthop Relat Res 2004;(418):67-73.

8. Peters CL, Erickson JA. Treatment of femoro-acetabular impingement with surgical dislocation and débridement in young adults. J Bone Joint Surg Am 2006;88(8):1735-41.

9. Beaulé PE, Harvey N, Zaragoza E, Le Duff MJ, Dorey FJ. The femoral head/neck offset and hip resurfacing. J Bone Joint Surg Br 2007;89(1):9-15.

10. Espinosa N, Beck M, Rothenfluh DA, Ganz R, Leunig M. Treatment of femoro-acetabular impingement: preliminary results of labral refixation. Surgical technique. J Bone Joint Surg Am 2007;89 Suppl 2 Pt 1:36-53.
11. Byrd JW, Jones KS. Prospective analysis of hip arthroscopy with 10-year followup. Clin Orthop Relat Res 2010;468(3):741-6. CrossRef

12. Philippon MJ, Briggs KK, Yen YM, Kuppersmith DA. Outcomes following hip arthroscopy for femoroacetabular impingement with associated chondrolabral dysfunction: minimum twoyear follow-up. J Bone Joint Surg $\mathrm{Br}$ 2009;91(1):16-23. CrossRef

13. Larson CM, Giveans MR. Arthroscopic management of femoroacetabular impingement: early outcomes measures. Arthroscopy 2008;24(5):540-6. CrossRef

14. Bedi A, Chen N, Robertson W, Kelly BT. The management of labral tears and femoroacetabular impingement of the hip in the young, active patient. Arthroscopy 2008;24(10):113545. CrossRef

15. Botser IB, Smith TW Jr, Nasser R, Domb BG. Open surgical dislocation versus arthroscopy for femoroacetabular impingement: a comparison of clinical outcomes. Arthroscopy 2011;27(2):270-8. CrossRef

16. Clohisy JC, Carlisle JC, Trousdale R, Kim YJ, Beaule PE, Morgan P, Steger-May K, Schoenecker PL, Millis M. Radiographic evaluation of the hip has limited reliability. Clin Orthop Relat Res 2009;467(3):666-75. CrossRef

17. Matsuda DK, Carlisle JC, Arthurs SC, Wierks CH, Philippon MJ. Comparative systematic review of the open dislocation, mini-open, and arthroscopic surgeries for femoroacetabular impingement. Arthroscopy 2011;27(2):252-69. CrossRef

18. Ross JR, Schoenecker PL, Clohisy JC. Surgical dislocation of the hip: evolving indications. HSS J 2013;9(1):60-9. CrossRef

19. Leunig M, Ganz R. Evolution of technique and indications for the Bernese periacetabular osteotomy. Bull NYU Hosp Jt Dis 2011;69 Suppl 1:S42-6.

20. Matsuda DK, Gupta N, Hanami D. Hip arthroscopy for challenging deformities: global pincer femoroacetabular impingement. Arthrosc Tech 2014;3(2):e197-204. CrossRef

21. McCarthy JC. Hip arthroscopy: when it is and when it is not indicated. Instr Course Lect 2004;53:615-21.

22. Telleria JJ, Safran MR, Harris AH, Gardi JN, Glick JM. Risk of sciatic nerve traction injury during hip arthroscopy -is it the amount or duration? An intraoperative nerve monitoring study. J Bone Joint Surg Am 2012;94(22):2025-32.

23. Bartlett CS, DiFelice GS, Buly RL, Quinn TJ, Green DS, Helfet DL. Cardiac arrest as a result of intraabdominal extravasation of fluid during arthroscopic removal of a loose body from the hip joint of a patient with an acetabular fracture. J Orthop Trauma 1998;12(4):294-9.

24. Gautier E, Ganz K, Krügel N, Gill T, Ganz R. Anatomy of the medial femoral circumflex artery and its surgical implications. J Bone Joint Surg Br 2000;82(5):679-83.

25. Brooker AF, Bowerman JW, Robinson RA, Riley LH Jr. Ectopic ossification following total hip replacement. Incidence and a method of classification. J Bone Joint Surg Am 1973;55(8):1629-32.

26. Leunig M, Werlen S, Ungersböck A, Ito K, Ganz R. Evaluation of the acetabular labrum by MR arthrography. J Bone Joint Surg Br 1997;79(2):230-4.

27. Dall D. Exposure of the hip by anterior osteotomy of the greater trochanter. A modified anterolateral approach. J Bone Joint Surg Br 1986;68(3):382-6.

28. Leunig M, Nho SJ, Turchetto L, Ganz R. Protrusio acetabuli: new insights and experience with joint preservation. Clin Orthop Relat Res 2009;467(9):2241-50. CrossRef 
29. McBride MT, Muldoon MP, Santore RF, Trousdale RT, Wenger DR. Protrusio acetabuli: diagnosis and treatment. J Am Acad Orthop Surg 2001;9(2):79-88.

30. Konan S, Rhee SJ, Haddad FS. Hip arthroscopy: analysis of a single surgeon's learning experience. J Bone Joint Surg Am 2011;93 Suppl 2:52-6. CrossRef

31. Sink EL, Beaulé PE, Sucato D, Kim YJ, Millis MB, Dayton M, Trousdale RT, Sierra RJ, Zaltz I, Schoenecker P, Monreal A, Clohisy J. Multicenter study of complications following surgical dislocation of the hip. J Bone Joint Surg Am 2011;93(12):1132-6. CrossRef

32. Clarke MT, Arora A, Villar RN. Hip arthroscopy: complications in 1054 cases. Clin Orthop Relat Res 2003;(406):84-8.

33. Ilizaliturri VM Jr. Complications of arthroscopic femoroacetabular impingement treatment: a review. Clin Orthop Relat Res 2009;467(3):760-8. CrossRef

34. Chung SM. The arterial supply of the developing proximal end of the human femur. J Bone Joint Surg Am 1976;58(7):961-70.

35. Nötzli HP, Siebenrock KA, Hempfing A, Ramseier LE, Ganz R. Perfusion of the femoral head during surgical dislocation of the hip. Monitoring by laser Doppler flowmetry. J Bone Joint Surg Br 2002;84(2):300-4.

36. Tibor LM, Sink EL. Pros and cons of surgical hip dislocation for the treatment of femoroacetabular impingement. J Pediatr Orthop 2013;33 Suppl 1: S131-6. CrossRef

37. Ayeni OR, Naudie D, Crouch S, Adili A, Pindiprolu B, Chien T, Beaulé PE, Bhandari M. Surgical indications for treatment for femoroacetabular impingement with surgical hip dislocation. Knee Surg Sports Traumatol Arthrosc 2013;21(7):1676-83. CrossRef

38. Beaulé PE, Shim P, Banga K. Clinical experience of Ganz surgical dislocation approach for metal-on-metal hip resurfacing. J Arthroplasty 2009;24(6 Suppl):127-31. CrossRef

39. Bedi A, Zaltz I, De La Torre K, Kelly BT. Radiographic comparison of surgical hip dislocation and hip arthroscopy for treatment of cam deformity in femoroacetabular impingement. Am J Sports Med 2011;39 Suppl:20S-8S. CrossRef

40. Schoenecker PL, Clohisy JC, Millis MB, Wenger DR. Surgical management of the problematic hip in adolescent and young adult patients. J Am Acad Orthop Surg 2011;19(5):275-86.

41. Mogensen B, Brattström H, Ekelund L, Svantesson H, Lidgren L. Synovectomy of the hip in juvenile chronic arthritis. J Bone Joint Surg Br 1982;64(3):295-9.
42. Fitzgerald RH Jr. Acetabular labrum tears. Diagnosis and treatment. Clin Orthop Relat Res 1995;(311):60-8.

43. Wood JB, Klassen RA, Peterson HA. Osteochondritis dissecans of the femoral head in children and adolescents: a report of 17 cases. J Pediatr Orthop 1995;15(3):313-6.

44. Bowen JR, Kumar VP, Joyce JJ 3rd, Bowen JC. Osteochondritis dissecans following Perthes' disease. Arthroscopic-operative treatment. Clin Orthop Relat Res 1986;(209):49-56.

45. Bastian JD, Büchler L, Meyer DC, Siebenrock KA, Keel MJ. Surgical hip dislocation for osteochondral transplantation as a salvage procedure for a femoral head impaction fracture. J Orthop Trauma 2010;24(12):e113-8. CrossRef

46. Leunig M, Tibor LM, Naal FD, Ganz R, Steinwachs MR. Surgical technique: Second-generation bone marrow stimulation via surgical dislocation to treat hip cartilage lesions. Clin Orthop Relat Res 2012;470(12):3421-31. CrossRef

47. Beaulé PE, Le Duff MJ, Zaragoza E. Quality of life following femoral head-neck osteochondroplasty for femoroacetabular impingement. J Bone Joint Surg Am 2007;89(4):773-9.

48. Clohisy JC, St John LC, Schutz AL. Surgical treatment of femoroacetabular impingement: a systematic review of the literature. Clin Orthop Relat Res 2010;468(2):555-64. CrossRef

49. Murphy S, Tannast M, Kim YJ, Buly R, Millis MB. Debridement of the adult hip for femoroacetabular impingement: indications and preliminary clinical results. Clin Orthop Relat Res 2004;(429):178-81.

50. Peters CL, Schabel K, Anderson L, Erickson J. Open treatment of femoroacetabular impingement is associated with clinical improvement and low complication rate at short-term followup. Clin Orthop Relat Res 2010;468(2):504-10. CrossRef

51. Yun HH, Shon WY, Yun JY. Treatment of femoroacetabular impingement with surgical dislocation. Clin Orthop Surg 2009;1(3):146-54. CrossRef

52. Smoll NR. Variations of the piriformis and sciatic nerve with clinical consequence: a review. Clin Anat 2010;23(1):8-17. CrossRef

53. Kempthorne JT, Armour PC, Rietveld JA, Hooper GJ. Surgical dislocation of the hip and the management of femoroacetabular impingement: results of the Christchurch experience. ANZ J Surg 2011;81(6):446-50. 